\title{
Crystallization of some anorthite-diopside glass precursors
}

\author{
C. LEONELLI, T. MANFREDINI, M. PAGANELLI, P. POZZI, G. C. PELLACANI \\ Dipartimento di Chimica, Università di Modena, Via Campi 183, 41100 Modena, Italy
}

Anorthite and diopside have been obtained from complete devitrification of glasses belonging to the quaternary system $\mathrm{MgO}-\mathrm{CaO}-\mathrm{Al}_{2} \mathrm{O}_{3}-\mathrm{SiO}_{2}$. Microstructure, the natural trend of the nucleation mechanism and kinetic studies on the crystallization phenomenon have been investigated by means of optical and electron microscopies, thermal and thermomechanical techniques and $X$-ray powder diffractometry. All the glasses investigated show a complete crystallization starting from a simple surface nucleation process. The activation energy for the crystallization process proved to be higher than that for viscous flow, leading to an important aspect modification in the sample during ceramization. Thermal stability and physical properties of both glass and glass-ceramic materials have been tested, suggesting the possible use of these materials in industrial application.

\section{Introduction}

Glass-ceramics are microcrystalline materials obtained from a parent glass by almost complete devitrification. Controlled crystallization of glass, starting from a heterogeneous or homogeneous nucleation process, can occur in two different ways depending on the nature of the nucleation mechanism. If nucleation occurs at a phase boundary between the vessel surface or air and the glass, the crystallization proceeds from the glass surface into the bulk material (surface crystallization).

The other type of nucleation (internal crystallization) can usually be achieved with a simple two-step heat-treatment; the first step is an isotherm at a temperature at which the mobility of atoms in the glass is sufficient for embryo formation and then nucleus growth. The second step is necessary to enhance crystal growth up to the desired size homogeneously dispersed in the volume [1].

Surface crystallization is favoured more than internal crystal nucleation, which generally necessitates the addition of nucleating agents. In fact if the first step of internal nucleation is ignored, only the surface and impurities inside the glass act as nuclei and the crystalline phase starts to grow on them.

Independent of nucleation mechanism, during crystal growth all mobile ions can move into the crystals leaving the glassy phase more and more viscous. This is the case for many glass-ceramic systems where the materials are partially devitrified in some preferential areas, leading to a dangerous anisotropy in chemical and physical properties [2-4].

Among glass-ceramic systems the quaternary $\mathrm{MgO}-\mathrm{CaO}-\mathrm{Al}_{2} \mathrm{O}_{3}-\mathrm{SiO}_{2}$ has been generally studied by considering the effect of the added oxides on the nucleation and crystallization mechanisms [1, 5-9]. In this paper we investigated the natural trend of the $\mathrm{MgO}-\mathrm{CaO}-\mathrm{Al}_{2} \mathrm{O}_{3}-\mathrm{SiO}_{2}$ system towards nucleation in the absence of nucleating agents [10] with the aim of identifying the nucleation mechanism, along with the determination of the crystal growth activation energy. Further interest derives from the standpoint that, since the phenomenon of great difference between the physico-chemical properties of the newly formed crystals and the remaining vitreous phase is very common, it seems very important, also for possible industrial applications, to plan the devitrification of particular types of crystal which will have physical and chemical characteristics similar to those of the starting glassy phase.

\section{Experimental procedure}

\subsection{Glass preparation}

The compositions studied are listed in Table I. They were prepared from high-quality oxides and carbonates, melted in mullite crucibles using an electric furnace and quenched either in water or on an iron mould to obtain respectively frits and bars suitable for thermomechanical testing. The fusion temperature was about $1370^{\circ} \mathrm{C}$ and in some cases a remelting of frits to assure homogeneity in the specimen was necessary. It has to be noted that the composition A75-D25 was not poured out of the crucible because of its partial devitrification and consequently exceptionally high viscosity. The chemical composition was checked to be constant even after the quenching process. No annealing treatment was performed either on the frits or on the bars.

\subsection{Crystallization process}

A quick heat treatment was used to prepare glassceramic samples: after heating at about $500^{\circ} \mathrm{C} \mathrm{h}^{-1}$ an isotherm step at $1100^{\circ} \mathrm{C}$ was held for $1 \mathrm{~h}$, and then the 
TABLE I Molar compositions ( $\%$ ) of the glasses studied

\begin{tabular}{llrlr}
\hline Composition & \multicolumn{4}{l}{ Content $(\mathrm{mol} \%)$} \\
\cline { 2 - 5 } & $\mathrm{SiO}_{2}$ & $\mathrm{Al}_{2} \mathrm{O}_{3}$ & $\mathrm{CaO}$ & $\mathrm{MgO}$ \\
\hline A25-D75 & 50.10 & 5.15 & 25.03 & 19.72 \\
A50-D50 & 50.07 & 10.93 & 25.03 & 13.97 \\
A75-D25 & 50.04 & 17.49 & 25.03 & 7.44 \\
\hline
\end{tabular}

specimens were extracted hot from the furnace and naturally cooled down to room temperature.

The crystal growth was followed by differential thermal analysis (DTA) in a Netzsch STA 409 thermobalance. Ground glassy frits with different grain sizes were heated at about $1400^{\circ} \mathrm{C}$ at different heating rates and DTA data were collected also during controlled cooling to $300^{\circ} \mathrm{C}$. Tests on bulk glass were performed using specimens in the form of the DTA platinum crucible.

Thermomechanical measurements were performed in a Netzsch dilatometer and collected both on glass bars and on glass-ceramic bars with a heating rate of $10^{\circ} \mathrm{C} \min ^{-1}$.

\subsection{Microstructural analysis}

The majority of microstructure studies on the crystallized glass were done by optical microscopy and by scanning electron microscopy (Philips PSEM 500). Sample preparation did not require any replica methods since freshly fractured or superficially etched specimens were suitable for this study.

Crystalline phases on glass-ceramic bar specimens, ground in an agate mill with agate balls for $20 \mathrm{~min}$ and sieved at $20 \mu \mathrm{m}$, were identified by X-ray powder diffractometry with nickel-filtered $\mathrm{Cu}_{\alpha}(\lambda=0.15418$ $\mathrm{nm}$, Philips PW 1050) with a $2 \mathrm{~s}$ time constant and 1000 counts range in the $2 \theta$ range from 10 to $45^{\circ}$ at a scanning rate of $1^{\circ} \mathrm{min}^{-1}$.

\section{Results and discussion}

\subsection{Thermal and thermomechanical results}

The compositions investigated belong to the region of glass formation in the ternary phase diagrams (Fig. 1) where pyroxenes (e.g. diopside) or anorthite are more stable [11]. The ease with which crystals are obtained from the melt of composition A75-D25 (Fig. 2), even during the quenching operations, impedes the formation of a pure glassy sample. Only A25-D75 and A50-D50 compositions transformed into glasses which were optically clear, bubble-free and homogeneous to polarized light.

The complete DTA thermograms of the three glass formulations investigated are shown in Fig. 3. Some very similar features of each thermogram are apparent:

(a) A reversible endothermic peak due to an increase of specific heat is present in the $720-740^{\circ} \mathrm{C}$ temperature range, signifying the glass transition $\left(T_{\mathrm{G}}\right)$. The peak maxima move slightly toward higher temperatures with increasing amount of anorthite in the samples.

(b) There is an exothermic event indicating crystallization $\left(T_{\mathrm{C}}\right)$ with a maximum at about $970-1000^{\circ} \mathrm{C}$ for all the glasses, which shifts by only $25^{\circ} \mathrm{C}$ to lower temperatures by increasing the anorthite content. A smaller peak area for composition A75-D25 confirms the presence of already crystallized material, which was absent in the other samples.

(c) An additional endothermic event, occurring at $1250-1300^{\circ} \mathrm{C}$, involves the melting of the glassy phases present. In particular, for the composition A25D75 a double melting peak is observed at 1300 and $1280^{\circ} \mathrm{C}$ : the first corresponds to the melting point of pure diopside, which is the main crystalline phase present, while the second can be correlated to that of the remaining glassy phase.

(d) During cooling an exothermic peak, well resolved from the melting point, is only observed for the A25-D75 and A50-D50 systems. This may indicate a crystallization process occurring during slow cooling, even though the drastic change in the physical state of the specimen can involve problems of interpretation. It is reasonable to assume, for these two compositions, that there exists a region of metastable non-crystalline state in a temperature range between the melting and crystallization temperatures. For the A75-D25 system, the presence of the lowest crystallization peak during heating and its absence during cooling indicates the initial existence of a crystalline phase which completes its formation during heating and does not melt at $1300^{\circ} \mathrm{C}$ to form an amorphous phase which could recrystallize during cooling at $900^{\circ} \mathrm{C}$. This can be a direct indication that this composition gives rise to an unstable amorphous state, explainable as an anorthite and glass solid solution.

An important observation can be made on considering that the exothermic crystallization peak does not double even in the case of composition A50-D50, where the formation of both anorthite and diopside is verified to occur simultaneously. This can be an indirect evaluation of the small difference between the activation energies of formation for the two crystals.

In order to evaluate the nucleation mechanisms of the A50-D50 and A25-D75 glasses, samples with different specific surface areas were studied by DTA. The increase of the specific surface area does not significantly influence the glass transition temperatures, whereas the crystallization peak maxima relevantly shift toward lower temperatures (Table II and Fig. 4). This observation and the absence of the splitting of the exothermic peak strongly suggest that the mechanism of crystal growth is essentially determined by the surface nucleation $[1,12]$. It is also noted that the transition temperatures of these glasses are located in a very narrow temperature range $\left(720-730^{\circ} \mathrm{C}\right)$ which does not move even while changing heating rate or particle size. This suggests that glasses from these compositions are quite stable up to the glass transformation temperature.

Thermomechanical behaviour of the parent glass and the crystallized material are very similar (Fig. 5), 